\title{
The generative loom: Tapestry in the community
}

\author{
Kirsty Darlaston
}

\begin{abstract}
This paper arises out of doctoral research into community responses to a tapestry woven on a loom in the public space of a local library. The research uncovered complex relationships between craft, making and the processes of viewing, all of which were informed by the embodied situated-ness of the people who proffered their insights at the loom. Throughout the conversations at the loom, the gestures and movements of the viewers of the tapestry came to the fore. This article explores some the embodied responses to the tapestry and situates these responses within a form of 'dynamic' interactive subjectivity.
\end{abstract}

\section{Preamble}

In 2008 I set up a tapestry loom at the City of Charles Sturt Civic Centre Library in Woodville as part of a doctoral research project. The design for the tapestry came out of a series of consultations with local community groups, such as cultural, sporting and community care groups. The interviewees were asked to bring along a textiles object that had some meaning to them and I photographed them with their object and recorded their stories. The tapestry design that resulted from these interviews consisted of woven strips of the photographed textile objects forming a map of the City of Charles Sturt. Previous community tapestry projects had caused me to be interested in the dialogue with community members that occurred at the loom, and how my presence as a working weaver and community artist facilitated these conversations. ${ }^{1}$ I would explain to visitors the process that had been undertaken with community members to come up with the design; as such I became a kind of proxy voice for the community members, imparting the importance of the textiles objects to them, retelling their stories and affirming their place on the map of the community. I began to feel that I was embodying and somehow performing for the public, a 'figure' of a craft maker, and that this figure bought out many memories of making that had threaded through peoples' lives.

This paper arises out of doctoral research into community responses to the City of Charles Sturt tapestry project. The research focused on comments made to myself, the weaver/researcher, as I wove a tapestry in my local library and it uncovered complex relationships between craft, making and the processes of viewing, all of which were informed by the embodied situatedness of people

1 For example: the Moonee Valley Tapestry Flag (2006); The Barbara Community Tapestry Project (1999-2001). 
who proffered their insights at the loom. The research held at its core the bodies of the maker and the viewer, the tapestry, and the tools and processes of making, and these were all central to the process of interactive subjectivity that took place at the loom. The research subjects (including myself as the weaver) were a dynamic force in the research. Laura Marks writes of an embodied haptic looking: '... it is less appropriate to speak of the object of the haptic look than to speak of a dynamic subjectivity between looker and image' (2002: 29). This is a form of relationship that does not focus on the boundaries of insider/ outsider, but instead allows for diverse knowledge and multiple experiences to cross-pollinate. This dynamism is generative, new possibilities are created by the motion between viewers and viewed, where neither becomes a static object, and both remain in a dance of subjectivity. The movements of making, the gestures of weaving that span time and culture, create this interrelationship. Makers, as well as cooks, launderers and cleaners, in communities all over the world, share similar actions. As Giorgia Volpe states, 'I think we all have an archaic memory of this gesture of weaving' (Volpe \& Bouillet 2001: 29). These shared bodily gestures, in all their variations, allow an embodied knowledge that is both individual and communal.

Throughout the loom conversations, the gestures and movements of the viewers of the tapestry came to the fore: one man made the gestures of flatbed cloth weaving, whilst he explained that his sister did this kind of work in Vietnam, another mimicked, moving his hand in waves, the 'under and over' movements that I made as I showed him the technique of weaving; a woman breathed 'beautiful' as she reached out to touch the tapestry. These embodied interactions are informed by textiles and by the processes of making textiles: small, recognisable, human movements. Luce Giard, in her 'Doing cooking' research, also highlights everyday gestures as a way of carving out a space in the world for oneself (1998). Giard lists the gestures that women perform as they shop, measure, chop, and so on, whilst they create daily meals. Food is consumed, intimately taken into the body; cloth evokes wrapping or covering the body. The gestures of cooking and weaving are gestures performed for the body, close to the body. Like Giard, this research was focused on the minutiae of small gestures, fragments of speech and short interactions as a way of working beyond dominant paradigms, moving into a more individualised space, a space where identities are processual and about becoming rather than fixed notions of being. This paper focuses on the generative possibilities of small encounters that occur through craft objects, particularly through the processes of making craft objects, by presenting short fragments of the loom conversations as examples of the embodied interactions that took place at the loom. The paper focuses on these small gestures and stories as a source of connection, which create spaces that bring together the multi-layered elsewheres of individual experiences. 
The generative loom: Tapestry in the community

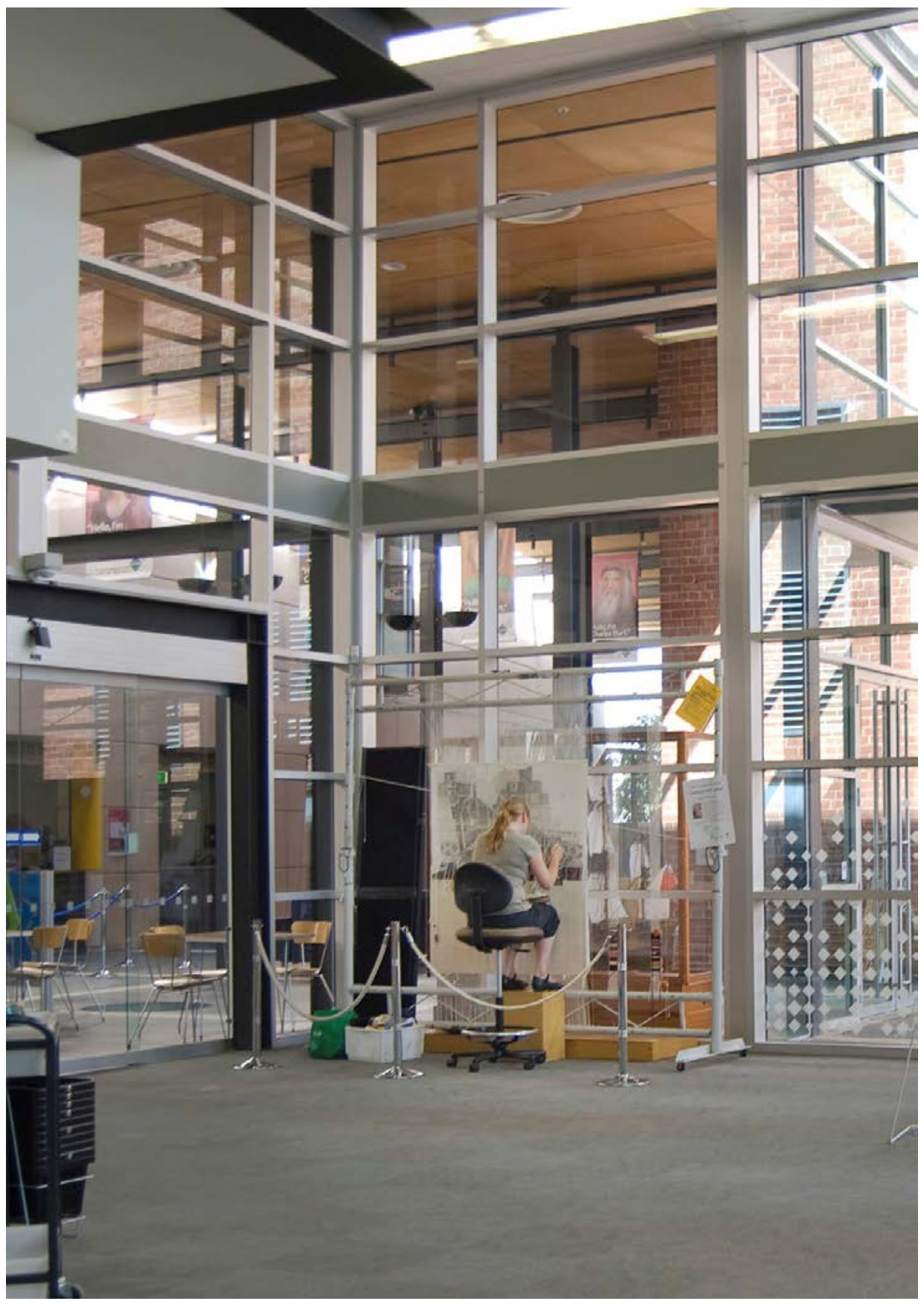

Figure 1. Kirsty Darlaston weaving the City of Charles Sturt Tapestry Map at the City of Charles Sturt Civic Centre Library, 2008.

Photograph: Elise De Simoni 


\section{Why do people tell me stories?}

Craft is intimately connected with story and narrative, and craft objects are embedded with the idea of sharing and telling. Esther Leslie discusses Benjamin's notions of making, narrative and wonder in her article: 'Walter Benjamin: Traces of craft' (1998). She relates Benjamin's correlation of storytelling with craft making in various ways, in particular through shaping raw matter into pattern and form: 'The story and the pot are formed by a life that has something to tell' (1998: 60). Leslie highlights Benjamin's use of the travelling journeyman and master craftsperson in his writing on alienation during the advent of mass-production in early industrialisation. Benjamin lamented the decline of the journeyman during this time and he foresaw a loss of storytelling practices as a result of this waning. In workshops, where travelling journeymen learnt techniques from master craftsmen, stories were told and news of the wider world was shared:

The best listeners, insists Benjamin, are the ones who have half-forgotten themselves, and while their half-conscious minds are engaged in potthrowing, spinning and weaving, and their bodies seized by the gentle rhythm of work, the stories they hear forego an existence on paper, imprinting themselves into the listeners' fantasy, awaiting retransmissions, after-lives. Storytelling is no simple form of time-passing. It mirrors a mode of processing and reconstituting experience. It intimates how experiences pass into and out of memory. For Benjamin, to reflect on the operations of storytelling, or craft communication and experience, is to ponder the arabesque of labour, experience and selfhood. (Leslie 1998: 5)

Here, the body's memory, the tacit knowledge of the maker as they perform repetitive and repeated tasks, combines with the evocation and reorganisation of memory during the retelling of stories. Research into the brain and memory has found that the brain makes new neural pathways during recollection as the retelling of a memory connects it to the time and place where it is retold (Grenier 2007: 330-31). Although the craftsperson may use age-old techniques and designs, these well-travelled pathways also lead to new connections and forms, growing from the body memory of the individual maker. The rhythms of the craftsperson working provide the perfect environment to soak in stories, the movements of work combining with the cadence of storytelling in a manner that induces the embodiment of the narrative. Leslies' eloquent phrasing: '... the arabesque of labour, experience and selfhood' (1998: 6) is reminiscent of Roland Barthes' use of the word 'figure' as '... the body caught in movement, rather than contemplated in repose' (Barthes 1977: 3-4): both making and storytelling are active in the construction of selfhood through movement and embodiment, rather than in abstract contemplation.

Sue Rowley discusses the entanglement of narrative and craft in her essay “"There once lived ...": Craft and narrative traditions', writing that 'The apparent affinity between stories and objects is by now an integral element in our response to craft' (1997: 80-81). Rowley goes on to chronicle the many ways in which craft and narrative are entwined, as shown through countless fairytales and common language terms that refer to crafted objects. She writes that 
the ubiquity of craft objects and processes in these stories are symptomatic of the importance of these objects to the construction of our identities, both personally and collectively. Storytelling and craft making are processes involved in the construction or performance of the self. As in Leslie's writing on Benjamin, storytelling and craft making here are 'mirror' to the mode of processing and reconstituting experience. Rowley sees these stories as subversive of dominant accounts of history:

what can we say about the insistent and recurring presence of craft objects - domestic artefacts, garments, treasures and trinkets - in our cultural stock of stories? Let's begin by noting that the rationalist-utilitarian ideologies and assumptions of modernism - the master narratives of histories of art and technology - are subverted by stories which accord to objects of everyday life a central role in the systems of cultural value and meaning. (1997: 79)

Working at the loom in the Woodville library, as well as on similar craft-based projects, has given me insight into the occurrence of personal stories about craft and making and the desire that people have to keep telling them. The tapestry invoked reactions that are personal, culturally embedded, and emotionally charged. Both storytelling and craft making are complex processes and they elicit complex responses; the loom stories were sometimes laced with pain and loss. The stories that I was told at the loom position textile objects and making processes as a pervasive force in our lives. We live in an information/machine age, but textiles have never been left behind in the race for faster, more efficient production and, indeed, the textiles industry was one of the earliest industries to be mechanised. Homemade crafts, objects made by hand, however, are still a 'common thread', as is shown by the resurgence of indie craft and 'do it yourself' movements in recent years. Crafting continues to maintain a place in our lives and in our constructions of selfhood. The following section focuses on Mahmoud's story, ${ }^{2}$ which he told to me at the loom during the weaving process, as well as fragments of other personal stories. These stories highlight the personal, the social, and the cultural meanings that emerge from making craft objects.

2 The names of research subjects have been changed for ethical purposes. Please note that the information presented in 'The story of Mahmoud' was collected from my first meeting with Mahmoud at the library and my subsequent working relationship with him on the Craftsouth Traditional Craft Skills Project. This differs from other interactions presented in this paper as it is developed from a series of conversations and interactions over the period of approximately one year. The information that I have presented is collated from my personal conversations and observations of Mahmoud during this time. 


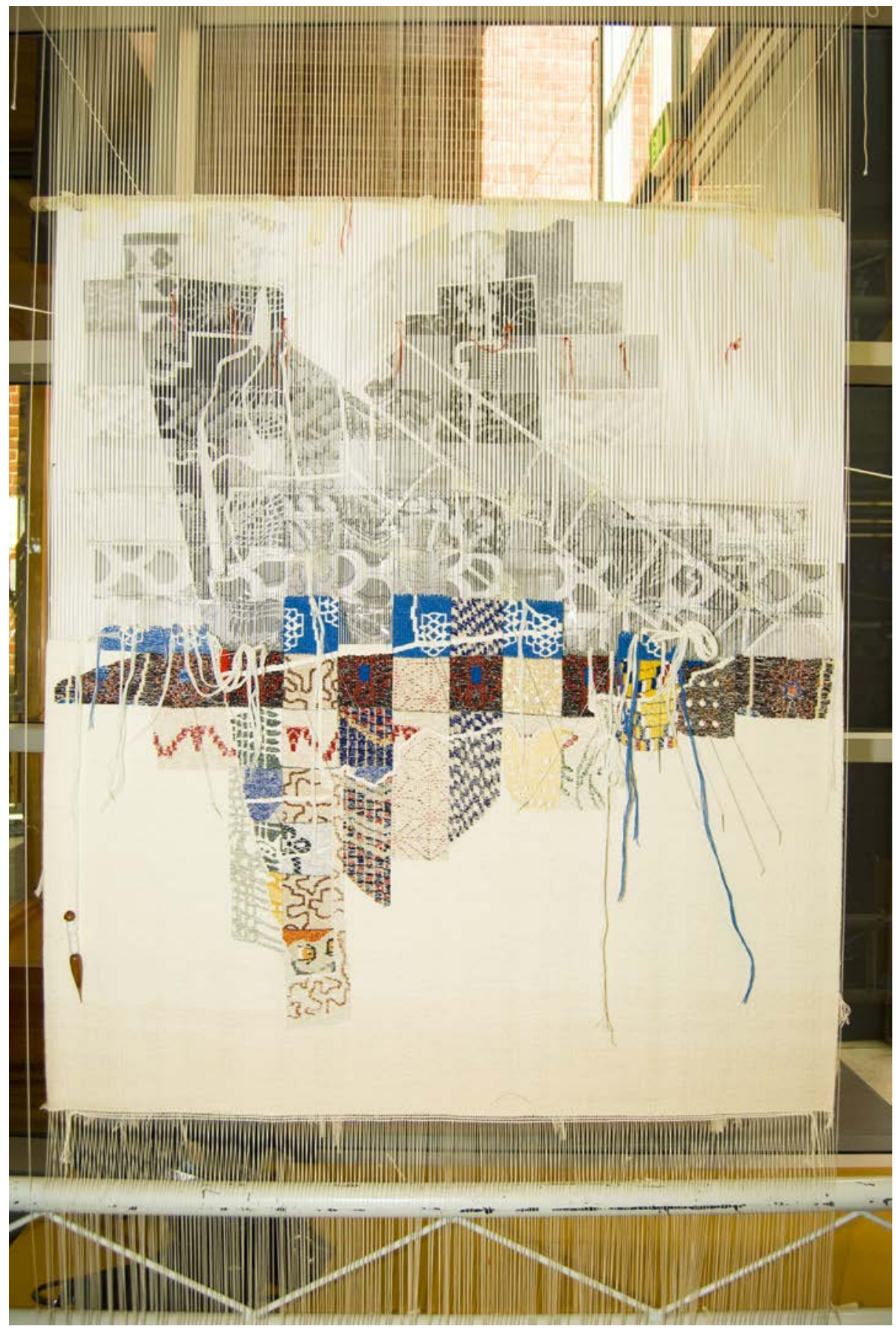

Figure 2. The City of Charles Sturt Tapestry Map at the City of Charles Sturt Civic Centre Library, 2008.

Photograph: Elise De Simoni 


\section{The story of Mahmoud}

When I first met Mahmoud in the Woodville library I wrote this in my field notes:

A man from Afghanistan came and looked at the tapestry. He was a rug weaver in Iran for 18 years - he moved there when he was 17 years old and learnt the trade. He used to do picture rugs - he made one of Lady Diana. He is going to bring in photos. He showed me how to do the Turkish Knot, one of the knots that he used and said that he will teach me others - we just need the correct hook to pull the wool through. He said tapestry weaving is too easy! [In comparison to rug weaving]. He appreciated the loom a lot. He had to leave all of his equipment behind in Iran. He is a very fast weaver but not very good at the tension [of the weft] as he is not used to it. He says he misses weaving a lot and is very pleased to see the tapestry.

What I didn't write in these notes was how excited Mahmoud was to see me weaving at the loom. He touched the bulk of the tapestry, touched and stretched the warps, picked up cops of wool from the boxes beside the loom and ran the threads through his fingers. At the time of our meeting, Mahmoud had not woven since leaving Afghanistan a few years earlier. Juhani Pallasmaa writes:

I confront the city with my body; my legs measure the length of the arcade and the width of the square; my gaze unconsciously projects my body onto the façade of the cathedral, where it roams over the mouldings and contours, sensing the size of recesses and projections (2005: 40).

Michael Taussig agrees, writing that we learn a city through using it (1991: 149). When Mahmoud met me at the loom, he began to navigate the tapestry through touch and movement. He tested and measured all of the objects around him his fingers felt the quality of the wool, the tension of the warp, and he tried to do a little bit of weaving. Through this process of embodied measuring and testing, Mahmoud was matching the knowledge that he had absorbed over his years of practicing rug making in Afghanistan and Iran with the tapestry practice that was before him in Australia - he was bringing his past and present together through the movements of his body. Tapestry weaving and knotted rug weaving are quite different techniques, but there are crossovers; for example, they have a similar system of warping. It seems that the tapestry and the weaver were sufficiently comparable to act as transitional objects into Mahmoud's past. Mahmoud made a further incursion into his memory by teaching me how to do a Turkish knot. Brockmeier writes that:

remembering the self depends not on restoring an original identity, but on remembering, on putting past and present selves together, moment by moment, in a process of provisional reconstruction. (2002, cited in Warin \& Dennis 2005: 168)

3 Field notes, Tuesday 3 June 2008. 


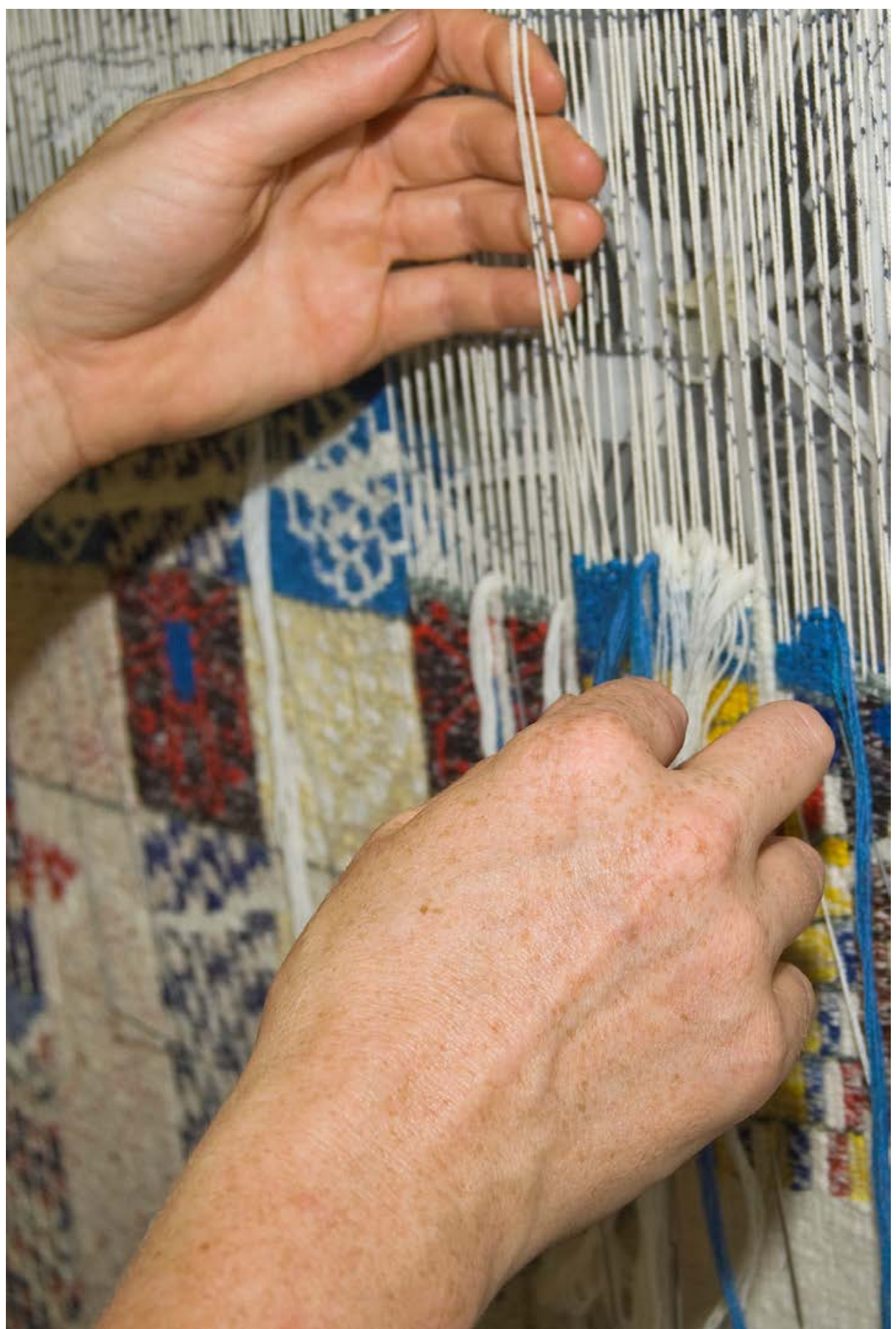

Figure 3. Kirsty Darlaston weaving the City of Charles Sturt Tapestry Map at the City of Charles Sturt Civic Centre Library, 2008.

Photograph: Elise De Simoni 
Mahmoud's gestures at the loom echo movements that he would have made when weaving rugs in Iran and Afghanistan. ${ }^{4}$ The testing of the tension of the warp and quality of weft wool are motions that are both unconscious and ubiquitous, fingers rubbing wool, pulling cotton warp - a sign of the weaver's sensual knowledge and experience. In some ways, Mahmoud was reconstructing a version of selfhood through making these familiar movements in less familiar surroundings.

Megan Warin and Simone Dennis have studied the sensual reconstruction of 'home' through the cooking and embroidery practices of 'Safieh', a woman who emigrated from Iran to Australia as a refugee. They found that through performing the embodied, everyday acts of cooking, eating, sharing food and smoothing embroidered cloths on a table, Safieh was able to recreate, in a new country, the sensuous patterns of her memories of her home. They write:

By including in her home in Australia the items that she has continually, habitually, corporeally and multisensually engaged with in her experiences of home in Iran, Safieh recreates a prior pattern of home place. (2005: 66)

This embodied engagement with her tools, ingredients and materials evoked a sense of home for Safieh in her new country, a process that Mahmoud was undergoing when he engaged with the tapestry - the recognition took place in his body. In Afghanistan and Iran the movements of rug weaving were mundane and everyday to Mahmoud - he spent many hours each day surrounded by the tools, materials, smells and textures of weaving. Rosalind Shaw writes '... there are other ways of remembering the past than by speaking of it ...' (2002: 2, cited in Morton 2007: 161). Habitual memory, or memory of habits, for Mahmoud, reside in his physical relationship with wool, warp, tools and movements of weaving. The gestures that Mahmoud performed in his daily weaving contain a meaning that was recreated when he handled the tools of weaving at my loom in the library. As Christopher Morton writes '... the traces of the past are not just found in our material surroundings, but also in our embodied skills and spatial orientations ...' (2007: 160).

\section{Conversation}

There is an implicit understanding between what I do at the loom and what Mahmoud remembers of his own work at looms in Iran and Afghanistan - a shared knowledge of textiles processes that transcends our backgrounds and experiences and allows us to communicate in a language of which we both have an understanding - to a certain extent. Homi Bhabha writes of the third space that opens up between two parties in the act of communication:

The act of interpretation is never simply an act of communication between the $\mathrm{I}$ and the You designated in the statement. The production of meaning

4 Mahmoud taught me how to weave rugs in a Craftsouth Traditional Craft Skills Workshops in 2010 and 2011. 
requires that these two places be mobilized in the passage through a Third Space, which represents both the general conditions of language and the specific implication of the utterance in a performative and institutional strategy of which it cannot 'in itself' be conscious. (1994: 53)

The techniques of rug weaving and tapestry, during our exchange at the loom, entered into Bhabha's 'Third Space', the space of translation. This is a space of possibilities, where the techniques had already become something else, beyond their context in the rug-weaving industry in Iran, beyond Mahmoud's memories and bodily movements, and beyond community tapestry in Australia and my memories and experiences.

Mahmoud demonstrated rug-weaving techniques on the warps of my tapestry and I taught him how to do tapestry weaving. The process of translation between the two techniques is aided by the translatability of one textiles medium to another - to a certain extent. Both Mahmoud and I possess a textiles 'language', gained through working in a medium over a period of time in, as Katherine Nolan and Victoria Mitchell write, '... the mutually constitutive relationship between body and material, that is the 'action' of the body on the textile and the textile on the body' (2010: 214). Both of us have a sense of recognition of how textiles behave, learnt through working with them with our fingers, arms, and eyes; we know about the stretch and tension of the warps, and how wool behaves. This language, or 'sensibility', allows for the third space that opens up between us to contain signs that we both recognise and can work with. Here, patterns of making translate into new patterns of understanding, as Nolan and Mitchell write:

The intercultural bleeds into the cross-cultural and even the criss-crosscultural, as textile processes and practices, in partnership with patterns, articulate the fabric of social exchange. (2010: 209)

\section{Economy}

Mahmoud asked why I was doing the tapestry, if it was my job, and if it was possible to make a living working as a weaver in Australia. It was clear to me that Mahmoud had not seen anything like tapestry, or his style of knotted rug weaving, since he had been in Australia. Mahmoud did not perform his weaving as a hobby, or as a professional artist in the sense of an artist having a solo practice and exhibiting their work. He worked for a company alongside other weavers, and clients from around the world commissioned his work; he often interpreted rugs from images that he was commissioned to weave, such as the photograph of Lady Diana and the King of Thailand. Unlike the loss of skill lamented in Benjamin's writing, his temporary exile from his craft is not the slow waning of artisanal work through the advent of industrialisation, but a rapid thrust into a different economy. The rug industry in Iran makes up a substantial part of the economy; there is a very small rug industry in Australia and designers often send their work overseas to be woven. Mahmoud experienced a wrench out of his home (two homes, really - Mahmoud left Afghanistan as a refugee 
during the Soviet invasion and he left Iran when the government started to show prejudice towards Afghan people) into a place that has a different economy and where the rhythms and gestures that were the norm in his previous homes do not exist. As Lisa Law writes:

The absence of familiar material culture, and its subtle evocations of home, is surely one of the most profound dislocations of transnational migration. (2001: 277)

Thus Mahmoud's excitement when he encountered my weaving, it was something that similar to his craft, sharing rhythms and time frames. When Mahmoud encountered me weaving at the loom in the library he reactivated what Stephen Lindsay and Don Read call 'prior patterns of activation across entire networks' (1995: 1, cited in Warin \& Dennis 2005: 163). These networks, economies of being, are not just about workplace cultural practices, but are about the structure of whole towns and cities, patterns of living as they are interwoven with industry and commerce. For a brief moment, Mahmoud had found a temporary home at the loom - a space where he was still a respected 'master' of his craft. Law, in her study of Filipino domestic maids who meet every Sunday in Chater Square in Hong Kong, writes of the humanising effect of reading letters from home in this vast city:

The letters of overseas Filipino women represent tremendous subjective power, and Tadir has argued that letters represent 'doses of human time, time with subjective value'. As with photos, letters play a role in constituting Little Manilla's perceptual landscape, for not only do letters create human time, they create a place of contemplation and subjective meaning where Hong Kong is experienced from another perspective. (2001: 279-80)

The loom also represented a space of 'human time' for Mahmoud, a space where his subjective worth was recognised and a space where the small movements of making are like his home.

\section{'They do this in my country'}

A lot of the people who viewed the tapestry mistook tapestry weaving (woven on an upright loom) for another form of weaving - mainly flatbed cloth weaving. One of the Vietnamese library staff members told me that in her country they have machines to do weaving like this. She made the actions of using the machine with her hands - 'like this, like this', her foot stamping down to open the next shed. ${ }^{5}$ A man told me that his sister weaves in a factory in Vietnam making large floral fabrics. He mapped out the dimensions of the loom with his hands and arms and made weaving movements fast and high into the air. ${ }^{6}$ I was using the technique of Gobelin, high-warp tapestry weaving is distinctly European, however, many people recognised something in the tapestry-weaving

5 Field notes, Friday 30 May 2008.

6 Field notes, Friday 20 June 2008. 
process, which points to the ubiquity of weaving techniques - processes that have travelled across continents and over oceans and are deeply embedded in most cultures. David Sutton and Michael Hernandez, in their study of cooking tools, write: 'The value of an object is the reflection of the actions that people have performed with this object, its history' (2011: 22). When people saw me weaving, they saw the actions of other weavers reflected in mine - they saw their sister weaving; people from their 'home' countries, Vietnam, Afghanistan, England, weaving. Sutton and Hernandez continue:

tools have the potential to become voices in the kitchen, speaking to us of other times and places as they go about the business of preparing our daily fare (2011: 23).

Here, although the viewers were not directly engaged in the making of the tapestry, their interaction with the tapestry spoke to them of other times and places. Embedded in the process of tapestry weaving are other weavings viewers have witnessed around the world. The tapestry, it seems, becomes a space into which 'elsewheres' can be projected. When a man approached the loom, holding his heart, and says 'My country - we do this in my country, I forgot!'7 - he saw in the tapestry a place that he still calls home.

\section{Articulation}

Nikos Papastergiadis writes:

Most importantly, for people with a burning memory of home that is far away, there is also the knowledge that language can communicate a sense of home. Communication becomes knowledge. Knowing comes from communicating. (2006: 147)

Even though the people who spoke to me at the loom about seeing or doing weaving in their own countries did not speak very much English, and I have very little understanding of Arabic and none of Vietnamese or any other languages, we communicated through short phrases, and through gestures of making - and, in the case of a man from Afghanistan, through gestures of pure emotion (a hand on his heart). Morton, in summarising Shaw's concepts of memory, suggests that in memory there is a '... continuum running between more discursive and embodied forms of memory, rather than the dichotomy that is often assumed' (Shaw 2002, as summarised in Morton 2007: 161). In the interactions at the loom - the man creating a loom around him through gestures, mimicking the movements that he has seen his sister perform in her daily work, and the woman making the jerking movements of weaving that she remembers from her country - memory surfaces in both gesture and words, in both the discursive and the embodied. Here the body, in many ways, speaks louder than the voice, filling the air with enlarged gestures of making. Based in memory, these communications were part of an emotional landscape. Through

7 Field notes, Wednesday 21 May 2008. 
these communications a sense of connection, built through gestures and halting words, began to form at the loom; in some ways we were able to communicate profound meanings to each other across languages.

The story of Mahmoud and other people who met me at the loom is a story of communication - of articulating memory and selfhood through word and gesture, all facilitated through the craft object and making process. These small encounters are made intimate through the bodies that hold knowledge of making. Amanda Wise summarises Ghassan Hage:

He describes 'a sense of community as a sense of articulation to others, the feeling of connection, of sharing, or recognition' and says that a feeling of homeliness comes from all this. He reminds us that communities are not just imagined; they are 'also so many bodies relating to each other'. (Hage 2002: 162, as cited in Wise 2005: 177)

When people spoke to me at the loom, articulating things that matter through the matter of textile making, they were not just speaking of 'home', but were also engaged in creating new communities, a new home - one that Wise calls 'belonging' and Hage refers to as 'homeliness'. In some ways the tapestry loom became a third space - the ubiquity of textile-making processes opened up a space where communication could take place, created spaces where connection could be made by bringing together past experiences with current encounters of craft and making.

Kirsty Darlaston completed her $\mathrm{PhD}$, focusing on embodied encounters during a community tapestry project, in 2011. She has worked on a number of community tapestry projects in South Australia and Victoria and was the Project Officer for the Craftsouth Traditional Craft Skills Project. She has lectured in textiles at the University of South Australia and is currently Acting Head of Textiles at The Australian National University.

\section{References}

Barthes, R. 1977, A Lover's Discourse: Fragments, R. Howard (trans), London: Penguin Group.

Bhabha, H.K. 1994, The Location of Culture, Oxon and New York: Routledge.

Giard, L. 1998, 'Doing cooking', in M. de Certeau, L. Giard \& P. Mayol (eds), The Practice of Everyday Life, Volume Two: Living and cooking, Oxford University Press.

Grenier, L. 2007, 'On memory: Deborah Aschheim at the Mattress Factory', Textile: Journal of Cloth and Culture, vol. 5, no. 3, pp. 328-31.

Law, L. 2001, 'Home cooking: Filipino women and the geographies of the senses in Hong Kong', Ecumene: A Journal of Environment, Culture and Meaning, vol. 8 , no. 3, pp. 264-83. 
Leslie, E. 1998, 'Walter Benjamin: Traces of craft', Journal of Design History, vol. 11 , no. 1, pp. 5-13.

Marks, Laura U. 2002, Touch: Sensuous theory and multisensory media, Minneapolis: University of Minnesota Press.

Morton, C. 2007, 'Remembering the house: Memory and materiality in Northern Botswana', Journal of Material Culture, vol. 12, no. 2, pp.157-79.

Nolan, K. \& Mitchell, V., 2010, 'Staging material, performing culture', Textile: Journal of Cloth and Culture, vol. 8, no. 2, pp. 202-25.

Pallasmaa, J. 2005, The Eyes of the Skin: Architecture and the senses, Chichester: John Wiley and Sons.

Papastergiadis, N. 2006, Spatial Aesthetics: Art, place and the everyday, London: Rivers Oran Press.

Rowley, S. 1997, “"There once lived ...": Craft and narrative traditions', in S. Rowley (ed.), Craft and Contemporary Theory, Sydney: Allen and Unwin.

Sutton, D. \& Hernandez, M. 2007, 'Voices in the kitchen: Cooking tools as inalienable possessions', viewed 3 Jan. 2011, http://anthro.siuc.edu/sutton/ pages/voices_in_the_kitchen.pdf

Taussig, M. 1991, 'Tactility and distraction', Cultural Anthropology, vol. 6, no. 2.

Volpe, G. \& Bouillet, M. 2001, 'Bodies, clothes, skins: A conversation in Quebec', in S. Rowley (ed.) Reinventing Textiles: Gender and identity, Telos Art Publishing.

Warin, W. \& Dennis, S. 2005, 'Threads of memory: Reproducing the Cypress Tree through sensual consumption', Journal of Intercultural Studies, vol. 26 nos 1 \& 2, pp. 159-70.

Wise, M. 2005, 'Hope and belonging in a multicultural suburb', Journal of Intercultural Studies, vol. 26, nos 1 \& 2, pp. 171-86. 